\title{
Federalismo Cooperativo, Regionalização e o Perfil de Governança Institucional das Comissões Intergestores Regionais no Brasil
}

\author{
Cooperative Federalism, Regionalization and the Institutional \\ Governance Profile of Regional Intergovernmental Commissions \\ in Brazil
}

Assis Mafort Ouverney (https://orcid.org/0000-0002-8581-3777) ${ }^{1}$

André Luis Bonifácio de Carvalho (https://orcid.org/0000-0003-0328-6588) ${ }^{2}$

José Mendes Ribeiro (http://orcid.org/0000-0003-0182-395X) ${ }^{1}$

Marcelo Rasga Moreira (http://orcid.org/0000-0003-3356-7153) ${ }^{1}$
${ }^{1}$ Departamento de Ciências Sociais, Escola Nacional de Saúde Pública Sergio Arouca, Centro de Estudos Estratégicos, Fundação Oswaldo Cruz. R. Leopoldo Bulhões 1480, Manguinhos. 21041-210 Rio de Janeiro RJ Brasil.

assismafort@gmail.com ${ }^{2}$ Departamento de Promoção da Saúde, Universidade Federal da Paraíba. João Pessoa PB Brasil.

\begin{abstract}
The scope of this article is to present and analyze the institutional governance profile of the 434 regional interagency committees operating in 25 states of the Brazilian Federation. The data were taken from the National Survey of Regional Interagency Committees (CIR), a census conducted in the years 2017 and 2018, and were collected through a questionnaire applied to the coordinators/directors/presidents of the CIR. The composition of the CIR profile was carried out using an analysis matrix specifically developed for this study, which combines 23 variables organized in five dimensions of institutional governance: institutional legitimacy, compliance and consistency of operation, quality of structure and operating conditions, federative equilibrium and quality of decision-making. The results show, on the one hand, an interagency institutional governance system consolidated throughout the national territory, with significant acceptance by the state and municipal spheres and clearly defined and publicized operating rules. On the other hand, it reveals a complex of levels characterized by marked limitations in financial and human resources and management infrastructure, in addition to action concentrated on emergency problems in the management of the network of health care and services.

Key words Federalism, Regionalization, Governance, Interagency Commissions
\end{abstract}

Resumo Este artigo tem por objetivo apresentar e analisar o perfil de governança institucional das 434 comissões intergestores regionais em funcionamento em 25 estados da federação brasileira. Os dados são da Pesquisa Nacional das Comissões Intergestores Regionais (CIR), um estudo censitário realizado nos anos de 2017 e 2018, e foram coletados por meio de um questionário aplicado aos coordenadores/diretores/presidentes das CIR. A composição do perfil das CIR foi realizada empregando uma matriz de análise especificamente desenvolvida para este estudo, que combina 23 variáveis organizadas em cinco atributos da governança interna dessas instâncias: legitimidade institucional, adesão e regularidade de funcionamento, qualidade da estrutura e condições de funcionamento, equilíbrio federativo e qualidade do processo decisório. Os resultados mostram, por um lado, um sistema de governança institucional intergestores consolidado em todo o território nacional, com significativa adesão das esferas estadual e municipal e regras de funcionamento definidas e publicizadas. Por outro, um complexo de instâncias caracterizadas por expressivas limitações de recursos financeiros, humanos e de infraestrutura de gestão e atuação concentrada em problemas emergenciais da gestão da rede de ações e serviços de saúde.

Palavras-chave Federalismo, Regionalização, Governança, Comissões Intergestores 


\section{Introdução}

O desenho federativo definido na Constituição de 1988 e nas Leis Orgânicas da Saúde alterou profundamente a natureza das relações intergovernamentais no setor saúde, favorecendo a emergência de uma governança de natureza mais cooperati$\mathrm{va}^{1}$. A consolidação desse formato específico de federalismo no SUS envolveu a construção de um arcabouço político-institucional em que as comissões intergestores assumiram um papel central como fóruns de apresentação de propostas, discussão de alternativas e estabelecimento de pactos confiáveis entre as três esferas de governo. A atuação regular e adequada da Comissão Intergestores Tripartite (CIT) e das Comissões Intergestores Bipartite (CIB) contribuiu de forma expressiva para gerenciar os dilemas do processo de descentralização e implantação do SUS².

A implantação das CIR, desde 2011,em continuidade aos Colegiados de Gestão Regional (CGR), tem sido apontada como a reafirmação de uma das inovações essenciais para se avançar no processo de articulação regional das ações e serviços nas 438 regiões de saúde do país ${ }^{3}$. A regionalização, entretanto, impõe novos desafios ao federalismo setorial, exigindo o desenvolvimento de soluções clínicas, gerenciais, financeiras e, principalmente, políticas, o que provoca uma reflexão do quanto esse sistema mais recente de governança está preparado para fornecer respostas adequadas para o futuro do SUS 4 .

As pesquisas nacionais existentes sobre as CIR, ou mesmo sobre seus predecessores - os CGR, institucionalizados pelo PACTO PELA SAÚDE de 2006 -, são escassas ${ }^{5}$, sendo a maioria dos estudos voltados para a realidade de regiões de saúde ou estados específicos ${ }^{6,7}$.

Esse artigo busca contribuir para superar essa restrição, ao apresentar e comparar as características de organização e de funcionamento das 434 CIR ativassem 25 estados da federação brasileira, analisando o perfil de sua governança institucional. Os dados são provenientes da Pesquisa Nacional das Comissões Intergestores Regionais (CIR), um estudo censitário realizado nos anos de 2017 e 2018, e foram coletados por meio de um questionário aplicado aos coordenadores/diretores/presidentes das CIR.

\section{Descentralização, federalismo cooperativo e o papel das Comissões Intergestores}

Nas últimas três décadas, a descentralização do SUS promoveu mudanças simultâneas na di- visão federativa das atribuições, na organização e gestão da rede de serviços, na elaboração, implementação e avaliação de políticas e programas, no financiamento e na tomada de decisões.

Em todas essas dimensões, observou-se a transferência de competências da União para os estados e municípios, que assumiram, em seus respectivos territórios, a gestão operacional do SUS, enquanto as instâncias centrais se especializaram na formulação, apoio à implementação, e avaliação de políticas e programas considerados de expressiva relevância ${ }^{8,9}$.

A estratégia adotada ao longo da descentralização do SUS visou constituir um modelo de pactos de trabalho conjunto e articulação entre as esferas da federação em torno de objetivos comuns, o que pode ampliar a funcionalidade das ações e fortalecer a interdependência como estratégias de coordenação federativa ${ }^{10}$.

Esse processo foi marcado pela constante necessidade de construir soluções federativas conjuntas para questões essenciais como definir quais responsabilidades os estados e municípios iriam assumir, como adaptar as estratégias de descentralização aos diversos contextos regionais do país, quais os patamares de contribuição das esferas no financiamento, como resolver os conflitos gerados pelas barreiras de acesso nos territórios, quais critérios adotar na alocação regional dos recursos de transferências federais, de forma abordar crises de funcionamento da rede de serviços, entre outras ${ }^{11}$.

As comissões intergestores tiveram um papel essencial nesse processo. Implementadas, efetivamente, nos primeiros anos da década de 1990, como parte da estratégia na NOB 93, desde então têm sido as principais instâncias de coordenação política do pacto federativo setorial. O sistema de comissões intergestores se consolidou como centro da dinâmica das relações intergovernamentais da política de saúde nos períodos seguintes e atualmente está bem estabelecido tanto em âmbito nacional quanto estadual ${ }^{12}$.

A CIT, prestes a completar 30 anos de atuação, hoje é reconhecida como o principal fórum setorial de tomada de decisões em âmbito nacional. Suas disposições orientam os gestores das três esferas e fornecem validade às novas diretrizes consideradas essenciais ao aperfeiçoamento do SUS. A legitimidade de suas decisões resulta da presença dos representantes legalmente constituídos das três esferas: o Ministério da Saúde, o Conselho Nacional dos Secretários Estaduais de Saúde (CONASS) e o Conselho Nacional das Secretarias Municipais de Saúde (CONASEMS). 
Nos estados, as comissões intergestores bipartite (CIB) são responsáveis por aprofundar e adaptar as decisões nacionais aos contextos estaduais, fornecer visibilidade às questões e problemas regionais e buscar a pactuação de soluções adequadas entre os gestores estaduais e municipais. A representação oficial das esferas envolvidas também é garantida em todas as decisões que consagraram a regra de consenso como o formato universal para a obtenção dos acordos intergestores, seguindo o modelo nacional ${ }^{13,14}$.

As Comissões Intergestores Regionais (CIR) representam a extensão desse sistema de governança integrada e consensuada, construído ao longo do processo de implementação do SUS, para o território das regiões de saúde. Instituídas pelo Decreto $7.508 / 2011^{15}$, as CIR buscam aperfeiçoar o modelo dos colegiados de gestão regional estabelecido no Pacto pela Saúde de $2006^{16}$.

Segundo a Resolução CIT 01/2011 ${ }^{17}$, que define suas atribuições, compete às CIR, no âmbito das respectivas regiões de saúde, pactuar sobre questões relacionadas a RENASES e RENAME, critérios de acessibilidade e escala, planejamento regional, diretrizes para redes de atenção, responsabilidades dos entes federados nas regiões de saúde, monitoramento e execução do COAP, entre outras atribuições de extrema relevância para o avanço da regionalização.

As CIR, por um lado, permitem que se amplie a capacidade de coordenação federativa da política de saúde sobre a dinâmica de gestão das relações intermunicipais. Por outro lado, também significam a disponibilização de um canal político exclusivo para que os municípios possam discutir com o gestor estadual as singularidades de cada região de saúde com maior profundidade e detalhamento do que poderiam fazê-lo nas reuniões da CIB.

Assim, tais comissões regionais possuem potencial para apoiar a construção de estratégias estaduais e nacionais voltadas para superar os principais obstáculos à regionalização do SUS, tais como a limitação de recursos financeiros e a judicialização ${ }^{18}$. Segundo estudo recente, com 3.899 secretários municipais de saúde, o fortalecimento das CIR foi apontado como uma das principais estratégias para que se garanta o aprimoramento do processo de planejamento e de regionalização da política de saúde no Brasil ${ }^{19}$.

É imprescindível, entretanto, que as CIR apresentem níveis mínimos de qualidade institucional que garantam o cumprimento de seu papel de fortalecer o caráter cooperativo da governança regional do SUS ${ }^{20,21}$.

\section{Metodologia da pesquisa}

\section{Definindo o perfil de Governança das CIR}

\section{Parcerias e concepção do estudo}

A análise das características institucionais das CIR foi realizada no âmbito da "Pesquisa Nacional das Comissões Intergestores Regional (CIR)", realizada pela Escola Nacional de Saúde Pública Sergio Arouca (ENSP/Fiocruz) em parceria com o CONASS e CONASEMS, com o objetivo de analisar a capacidade de coordenação regional e o papel desempenhado pelas CIR na gestão do SUS nas regiões de saúde dos estados brasileiros. Compuseram a parceria também, ao longo do trabalho de campo, os COSEMS e as secretarias estaduais de saúde, que apoiaram a realização dos estudos desde a etapa de concepção do estudo até a coleta dos dados.

O estudo foi financiado pelo Ministério da Saúde, no âmbito do Termo de Execução Descentralizada (TED) No 30/2015, e foi realizado em duas etapas, sendo a primeira direcionada para avaliar a qualidade da governança institucional e a segunda voltada para analisar a capacidade das CIR para apoiar o planejamento e a gestão de políticas. Os resultados apresentados nesse artigo se referem à primeira parte da pesquisa.

A elaboração da primeira fase da pesquisa começou em fevereiro de 2017, com a formação e o alinhamento da equipe de pesquisadores, que haviam sido selecionados por meio de edital público de ampla concorrência em dezembro de 2016. Esse processo envolveu a realização de oficinas de debate teórico, conceitual e metodológico a partir da revisão dos estudos existentes sobre as CIR nos estados brasileiros ${ }^{3,6,7}$.

A partir da revisão da literatura, tendo em vista a diversidade de conceitos de governança e diferentes áreas ${ }^{22,23}$, foi elaborado um conceito específico de governança para o estudo das CIR, com o objetivo eliminar as imprecisões e generalidades e estabelecer uma relação teórica mais direta com o papel dessas instâncias no processo de regionalização do SUS.

Para os efeitos dessa pesquisa, definiu-se a governança das CIR como a articulação entre a qualidade de organização institucional e a capacidade de apoiar o planejamento e a gestão de políticas de saúde em âmbito regional. Esse conceito abrange tanto a dimensão interna quanto a externa da CIR, adotando uma perspectiva ampla de governança, porém precisa, conceitualmente.

A organização institucional, dimensão interna, abrange 5 (cinco) atributos para análise: 
(1) legitimidade institucional, (2) adesão e regularidade de funcionamento, (3) qualidade de estrutura e condições de funcionamento, (4) equilíbrio federativo e (5) qualidade do processo decisório.

Por sua vez, a capacidade de atuação das CIR na política regional de saúde, dimensão externa, foi definida a partir de 7 (sete) propriedades: (1) qualificação das instâncias técnicas, (2) aprofundamento de análise dos temas relevantes, (3) permeabilidade do colegiado ao debate técnico (4) articulação de recursos estratégicos, (5) mobilização de atores relevantes, (6) protagonismo nos processos de planejamento regional em saúde e (7) centralidade na definição de estratégias de qualificação da gestão regional do SUS.

Esse artigo apresenta especificamente os resultados relativos à organização institucional das CIR, dimensão interna, cujas variáveis componentes dos 5 atributos acima apresentados serão definidas na seção de sistematização e análise dos dados.

Considerando a necessidade de elaborar um estudo nacional e extenso das características institucionais das CIR, garantir a comparabilidade dos resultados e obter dados para todo o país, optou-se, logo nas primeiras reuniões, pela realização de um censo a partir da aplicação de um questionário.

\section{Elaboração do questionário e realização do pré-teste}

A formulação das questões que compuseram o texto da base do questionário foi realizada ao longo dos meses de março e abril. Logo em seguida, procedeu-se a inserção das questões no software Survey Monkey ${ }^{24}$, considerando os ganhos de funcionalidade de gestão, praticidade de coleta, segurança, velocidade da tabulação e obtenção de resultados. Nessa fase, também foram conduzidos diversos testes pela equipe de pesquisa, visando avaliar a qualidade das funcionalidades programadas e mensurar o tempo médio de resposta do questionário.

Finalmente, em maio, foram realizadas oficinas com gestores e técnicos indicados pelas secretarias estaduais de saúde e COSEMS de cada estado, visando realizar o pré-teste do instrumento e construir a estratégia de aplicação do mesmo junto aos coordenadores/diretores/ presidentes da CIR nas regiões de saúde. Após os ajustes e correções realizadas a partir do pré-teste, o questionário era composto por 80 questões distribuídas nos cinco atributos de organização institucional abordadas acima.

\section{Estratégia de coleta de dados e realização dos estudos-pilotos estaduais}

Uma vez concluída a etapa de elaboração, os representantes de cada estado (SES e COSEMS) forneceram planilhas que continham os nomes, funções e os e-mails dos coordenadores/diretores/presidentes das respectivas regiões de saúde. Em seguida, foram organizados grupos de monitoramento por estado, compostos por, pelo menos, dois pesquisadores do grupo de coordenação da pesquisa e os representantes de SES e COSEMS. As listas de e-mails foram inseridas na plataforma do Survey Monkey e organizadas por estado e região de saúde.

Os links contendo o questionário da pesquisa foram enviados para cada um dos coordenadores/diretores/presidentes, seguindo uma sequência previamente definida em conjunto com os representantes de cada estado. Logo após o encaminhamento dos links, os pesquisadores enviavam também um e-mail explicando a natureza da pesquisa e a forma de preenchimento do questionário, além de disponibilizarem seus contatos pessoais para o esclarecimento dúvidas.

A estratégia de coleta de dados foi concebida de forma a ser iniciada nas cinco grandes regiões do país (Norte, Nordeste, Centro-Oeste, Sudeste e Sul), de forma simultânea, porém escalonada. Assim, foram escolhidos cinco estados, um em cada região, para testar a estratégia de implementação da pesquisa, sendo estes: Pará, Paraíba, Mato Grosso do Sul, Espírito Santo e Paraná.

\section{Monitoramento dos respondentes}

Ao longo de todo o processo de coleta dos dados, os pesquisadores mantiveram contato constante com os respondentes e com os representantes das SES e COSEMS, criando uma sistemática de acompanhamento conjunto diário, que envolveu, inclusive, a formação de grupos de Whatsapp de uso contínuo. Para cada estado, foi gerado um painel de monitoramento do retorno dos questionários, contendo informações sobre o estágio de preenchimento por CIR, tempo de preenchimento, percentual de questionário parciais e completos por UF, entre outros.

Mensalmente, eram realizadas reuniões de coordenação da pesquisa para avaliar o andamento da coleta dos dados, com análises por UF sobre o estágio de andamento da pesquisa e as estratégias adotadas para acelerar o preenchimento dos questionários. Periodicamente, eram enviados a CONASS e CONASEMS boletins de informação sobre o estágio de realização da pesquisa.

O processo completo de coleta de dados da primeira fase da pesquisa foi realizado em nove 
meses, indo de julho de 2017 a março de 2018 . Foram obtidos questionários completos para as CIR de 434 regiões de saúde, o que representa a realização de um censo nacional dessas instâncias. No total, o Brasil possui oficialmente 438 regiões de saúde. Não responderam o questionário apenas as duas regiões de Roraima e uma região de Rondônia em virtude de suas CIR não estarem funcionando nos últimos anos. Além dessas 3 regiões de saúde, o Distrito Federal também não foi incluído por não ser organizado territorialmente em municípios e, portanto, não possuir uma instância intergestores.

\section{Sistematização e análise dos dados}

\section{Definindo as dimensões e variáveis da Governança Institucional das CIR}

Concluída a fase de coleta, as informações armazenadas no Survey Monkey foram extraídas para um banco de dados em Excel para possibilitar a realização das análises de qualidade das respostas, quando foram eliminadas as possíveis duplicações, conferidas as denominações das regiões, verificada a lista dos nomes dos respondentes, etc. Em seguida, foram tabuladas as respostas fornecidas para a categoria “outros" presentes em diversas questões, assim como as respostas para questões abertas.

Esse artigo apresenta os resultados obtidos especificamente para a dimensão interna da governança das CIR, relacionada à qualidade de sua organização institucional. Como pode ser visualizado no Quadro 1, essa foi definida a partir de partir de 24 variáveis, distribuídas em cinco dimensões de análise: (1) legitimidade institucional, (2) adesão e regularidade de funcionamento, (3) qualidade da estrutura e condições de funcionamento e (4) equilíbrio federativo, (5) qualidade do processo decisório.

Assim, para analisar o nível de legitimidade institucional das CIR, foram selecionadas variáveis relacionadas a sua posição na estrutura organizacional da SES, o tipo de ato de criação, a presença e modo de elaboração e a forma de conduzir a implementação da CIR. Uma CIR bem posicionada, com regras definidas e implementada de forma conjunta apresenta-se como um espaço legítimo e com capacidade de influenciar a condução da política de saúde.

A adesão e regularidade de funcionamento foram dimensionadas não só pelos critérios clássicos de frequência de realização de reuniões e de comparecimento dos membros, mas também por informações sobre o tempo de implementação em relação à publicação do Decreto 7.508/2011, amplitude inicial de adesão dos municípios na região de saúde e a existência de interrupções de atividade.

Em relação à qualidade da estrutura e condições de funcionamento, foram empregados a presença de um espaço específico para atividades administrativas, número de salas e de computadores, o regime de funcionamento e número de funcionário da secretaria executiva, além do volume de recursos financeiros para o funcionamento às CIR.

O equilíbrio federativo foi analisado tanto pela composição do colegiado quanto pelas prerrogativas de condução de momentos relevantes no processo decisório, em especial a definição de pauta das reuniões do colegiado e a natureza dos convidados.

Finalmente, a qualidade do processo decisório foi avaliada buscando conhecer tanto a forma de organizar as decisões quanto o conteúdo dos debates, a partir de quatro variáveis: presença de reuniões técnicas prévias, quórum mínimo para abertura das reuniões, forma de participação dos convidados e principais temas discutidos.

\section{Resultados}

\section{Qual o perfil de Organização Institucional (Governança Interna) das CIR?}

\section{Legitimidade Institucional}

A maioria das CIR está vinculada às Diretorias Regionais de Saúde das SES (38\%) ou às CIB (34,6\%), como visto no Quadro 2, foi instituída por meio de deliberação da CIB $(74,4 \%)$ e possui regimento padronizado, publicado pelas SES $(54,4 \%)$. Em geral, os regimentos foram elaborados por meio de arranjos colaborativos envolvendo os gestores estaduais e os municipais $(80,9 \%)$ e o processo de implementação foi conduzido a partir de negociações realizadas na CIB (50,9\%).

$A$ vinculação institucional às CIB segue o estabelecido pelas instruções normativas da CIT, que definem a CIR como extensão regional do sistema estadual de pactuação intergestores, fornecendo-lhe maior legitimidade. $\mathrm{O}$ trabalho articulado das CIR com as DRS pode, por um lado, compor um arranjo com maior capacidade operacional para a gestão do sistema regional de saúde, mas, por outro, pode produzir desequilíbrios na relação federativa, ao ampliar as prerrogativas da SES. Arranjos mais centralizados na SES podem ainda exacerbar esse desequilíbrio. 
Quadro 1. Atributos e Variáveis da Organização Institucional das CIR.

I - Legitimidade Institucional

1. Inserção institucional da CIR

2. Tipo de legislação de criação

3. Existência e natureza do Regimento Interno

4. Forma de elaboração do Regimento Interno

5. Condução do processo de implantação

II - Adesão e Regularidade de Funcionamento

6. Forma de adesão dos municípios

7. Início efetivo de atuação da CIR

8. Interrupções no funcionamento da CIR

9. Frequência de ocorrência de reuniões ordinárias

10. Frequência de comparecimento dos membros

III - Qualidade de Estrutura e Condições de Funcionamento

11. Espaço administrativo e operacional

12. Número de Salas

13. Funcionamento da Secretaria Executiva

14. Número de funcionários da Secretaria Executiva

15. Volume global estimado de recursos financeiros

IV - Equilíbrio Federativo

16. Composição do colegiado da CIR

17. Fatores de definição da pauta das reuniões

18. Atores que definem a pauta das reuniões

19. Natureza dos convidados

V - Qualidade do Processo Decisório

20. Presença de reuniões técnicas prévias

21. Quórum mínimo para abertura das reuniões $\left(1^{\text {a }}\right.$ chamada)

22. Formas de participação dos convidados

23. Principais temas discutidos

Fonte: Elaborado pelos autores. Pesquisa Nacional das CIR (Centro de Estudos Estratégicos da Fiocruz).

A padronização dos regimentos internos das CIR de cada estado pode garantir a presença de um conjunto mínimo de regras comuns em todas as regiões de saúde, criando um sistema mais homogêneo, porém, pode também limitar a autonomia das regiões de saúde para definir suas próprias regras. Os resultados mostram que esse parece não ser o caso, uma vez que a maioria dos regimentos foi elaborada em grupos conjuntos de trabalho, na própria CIB ou com mediação do COSEM.

\section{Adesão e regularidade de funcionamento}

Em mais de três quartos das CIR (78,6\%), a adesão dos municípios foi imediata e completa, sendo que o início efetivo de atuação das mesmas ocorreu nos anos de 2011 e 2012 (53,9\%), portanto, logo após a edição do Decreto 7.508/11. A grande maioria dos coordenadores/presidentes de CIR também não relatou ter conhecimento da ocorrência de interrupções significativas desde o início e sua atuação $(78,1 \%)$.

Quase todas as CIR realizam suas reuniões mensalmente $(94,5 \%)$ e a estimativa de frequência média de comparecimento dos membros, na maioria das CIR $(63,8 \%)$, para 2016 , foi acima de $70 \%$.

A elevada adesão dos municípios às CIR pode ser explicada pela ampla difusão prévia dos colegiados de gestão regional nas regiões de saúde dos estados, ocorrendo, portanto, em grande parte, a substituição de um modelo institucional por outro.

O percentual das CIR que tiveram seu funcionamento iniciado em 2011/2012 também deveria seguir esse mesmo padrão, porém, uma parte expressiva dos coordenadores/presidentes estabeleceu, como data inicial, a relativa a modelos anteriores à CIR (22\%).

Quase todas as CIR realizam suas reuniões mensalmente $(94,5 \%)$ e a estimativa de frequência média de comparecimento dos membros, na maioria das CIR $(63,8 \%)$, para 2016, foi acima de $70 \%$.

\section{Qualidade da estrutura e condições de funcionamento das CIR}

Conforme mostrado no Quadro 2, mais de três quartos das CIR funcionam em espaços de propriedade da SES $(58,5 \%)$ ou alugado por elas $(16,8 \%)$ e possuem apenas uma sala para desenvolverem suas atividades (85,5\%). Há ainda diversos outros tipos de arranjos que foram mencionados pelos coordenadores/presidentes de CIR $(13,2 \%)$, tais como instalações do maior município da região, do COSEMS, do consórcio intermunicipal, de universidades, de instituições filantrópicas, entre outras. Os resultados mostram precariedade de infraestrutura de funcionamento e dependência das instalações das SES.

Quase três quartos $(73,7 \%)$ das CIR possuem uma secretaria executiva implementada, e mais da metade delas opera em regime de funcionamento diário (59,4\%). Mais de dois terços dessas secretarias executivas têm, a sua disposição, apenas $1(47,2 \%)$ ou $2(21,9 \%)$ funcionários, além do próprio secretário executivo, para realização de todas as tarefas cotidianas.

Essa reduzida disposição de recursos também se reflete na área orçamentária, pois mais de dois terços das CIR também contavam, para o ano de 2016, somente com, no máximo, $\mathrm{R} \$ 20$ mil para o financiamento anual de seus gastos de custeio e 


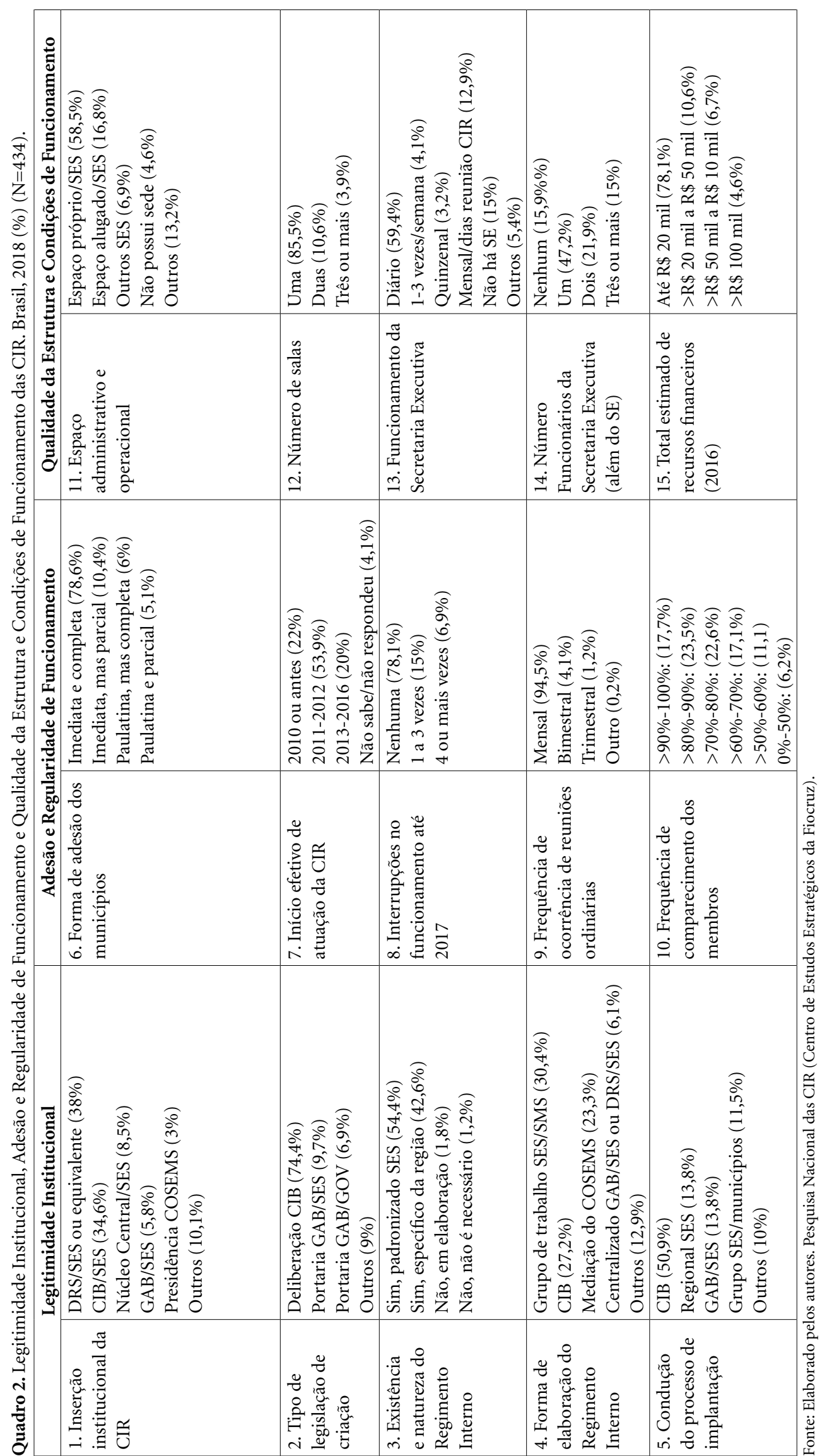


Quadro 3. Equilíbrio Federativo e Qualidade do Processo Decisório das CIR. Brasil, 2018 (\%) (N=434).

\begin{tabular}{|c|c|c|c|}
\hline \multicolumn{2}{|r|}{ Equilíbrio Federativo } & \multicolumn{2}{|r|}{ Qualidade do Processo Decisório } \\
\hline $\begin{array}{l}16 . \\
\text { Composição } \\
\text { do } \\
\text { Colegiado } \\
\text { da CIR } \\
\text { (mais } \\
\text { citados) }\end{array}$ & $\begin{array}{l}\text { Todos os SMS da região }(99,5 \%) \\
\text { Diretores regionais da SES }(78,1 \%) \\
\text { Representantes Diretoria COSEMS }(64,3 \%) \\
\text { Nível Central SES }(27,4 \%) \\
\text { Representantes MS }(12,4 \%) \\
\text { Diretores Hospitais Regionais }(11,5 \%)\end{array}$ & $\begin{array}{l}\text { 20. Presença } \\
\text { de reuniões } \\
\text { técnicas } \\
\text { prévias }\end{array}$ & $\begin{array}{l}\text { Regularmente }(36,2 \%) \\
\text { Convocação SE/Câmara Técnica }(34,1 \%) \\
\text { Convocação Coord./Presid. }(16,1 \%) \\
\text { Não há necessidade }(13,6 \%)\end{array}$ \\
\hline $\begin{array}{l}\text { 17.Atores } \\
\text { que definem } \\
\text { a pauta das } \\
\text { reuniões }\end{array}$ & $\begin{array}{l}\text { Presidente/coordenador }(74 \%) \\
\text { Membros do colegiado }(52,5 \%) \\
\text { Secretário Executivo (a) }(52,1 \%) \\
\text { Gestores/técnicos das SMS }(31,1 \%) \\
\text { Coordenador da câmara técnica }(21 \%) \\
\text { Gestores/técnicos da SES }(18,2 \%)\end{array}$ & $\begin{array}{l}\text { 21. Quórum } \\
\text { mínimo para } \\
\text { abertura das } \\
\text { reuniões }\left(1^{\mathrm{a}}\right. \\
\text { chamada })\end{array}$ & $\begin{array}{l}>30 \% \text { a } 50 \% \text { membros }(8,8 \%) \\
>50 \% \text { a } 60 \% \text { membros }(82,8 \%) \\
\text { Acima de } 60 \% \text { membros }(6 \%) \\
\text { Outros }(3,2 \%)\end{array}$ \\
\hline $\begin{array}{l}\text { 18. Fatores } \\
\text { de definição } \\
\text { da pauta } \\
\text { das reuniões } \\
\text { (mais } \\
\text { citados) }\end{array}$ & $\begin{array}{l}\text { Solicitações das SMS (88\%) } \\
\text { Decisões da CIB (77\%) } \\
\text { Solicitações da SES (67,3\%) } \\
\text { Demandas Câmara Técnica/CIR (59,7\%) } \\
\text { Legislação da CIT/MS (38,9\%) } \\
\text { Agenda do COSEMS (35\%) }\end{array}$ & $\begin{array}{l}\text { 22. Forma de } \\
\text { participação } \\
\text { dos } \\
\text { convidados }\end{array}$ & $\begin{array}{l}\text { Apresentações/informes e debates }(70,7 \%) \\
\text { Apresentações/informes }(21,9 \%) \\
\text { Apenas assistir }(7,4 \%)\end{array}$ \\
\hline $\begin{array}{l}\text { 19. Natureza } \\
\text { dos } \\
\text { convidados } \\
\text { (mais } \\
\text { citados) }\end{array}$ & $\begin{array}{l}\text { Gestores/técnicos da SES }(84,1 \%) \\
\text { Gestores/técnicos das SMS }(81,1 \%) \\
\text { Técnicos/apoiadores do COSEMS }(73,7 \%) \\
\text { Representantes hospitais privados/ } \\
\text { filantrópicos. }(38,7 \%) \\
\text { Representantes Consórcios }(22,6 \%)\end{array}$ & $\begin{array}{l}\text { 23. Principais } \\
\text { temas } \\
\text { discutidos } \\
\text { (mais } \\
\text { citados) }\end{array}$ & $\begin{array}{l}\text { Pactuação Fluxos intermunicipais }(68,9 \%) \\
\text { Credenciamento políticas federais }(62,7 \%) \\
\text { Problemas de saúde pública }(57,6 \%) \\
\text { Repasses financeiros da SES }(52,1 \%) \\
\text { Expansão e Qualificação da AB }(44,9 \%) \\
\text { Regulação rede privada/filantrópica }(32,5 \%)\end{array}$ \\
\hline
\end{tabular}

Fonte: Elaborado pelos autores. Pesquisa Nacional das CIR (Centro de Estudos Estratégicos da Fiocruz).

de investimentos, o que correspondente, em média, a $\mathrm{R} \$ 1.667,00$ mensais.

Durante as oficinas realizadas com representantes das SES e dos COSEMS, foram registrados diversos relatos de que muitas CIR ainda eram financiadas por recursos provenientes da Política Nacional de Gestão Estratégica e Participativa no SUS (ParticipaSUS).

\section{Equilíbrio federativo}

Conforme apresentado no Quadro 3, a composição do colegiado abrange essencialmente os secretários municipais de saúde, os diretores das regionais de saúde da SES, representantes dos COSEMS e representantes do nível central da SES. Em algumas CIR, foi relatada a participação de representantes do Ministério da Saúde e diretores de hospitais regionais.

A definição das pautas das reuniões não é prerrogativa exclusiva do presidente/coordenador ou do secretário executivo da CIR, uma vez que todos os membros que compõem o colegiado (secretários municiais e representantes da SES) também são atores relevantes na proposição de temas. Da mesma forma, gestores e técnicos estaduais e municipais que participam das reuniões realizando apresentações ou informes também influenciam esse processo, embora em proporção menor das CIR do que os demais atores.

A natureza federativa das CIR é corroborada pela presença dos secretários municipais de saúde e de representantes da SES em praticamente todas as regiões de saúde. A participação municipal envolve todos os secretários municipais de saúde em cada região, o que mostra não só a relevância atribuída às CIR pelos governos locais, mas também a capilaridade desse arranjo institucional. O mesmo de ser afirmado em relação aos governos estaduais.

Assim, a presença extensa de representantes de ambas as esferas permite compor pactos e consensos que levam a decisões marcadas por níveis mínimos de equilíbrio federativo, apesar de possíveis diferenças de poder e domínio de recursos em cada região de saúde.

Esse equilíbrio também pode ser encontrado no processo de definição das pautas das reuniões das CIR, momento em que se decide quem in- 
fluencia o que será discutido e debatido nas regiões de colegiado. Os principais fatores citados como sendo os de maior influência na definição das pautas são solicitações das secretarias municipais de saúde (88\%), decisões da CIB (77\%) e solicitações das secretarias estaduais de saúde $(67,3 \%)$. Novamente, os resultados mostram que as esferas estadual e municipal possuem acesso equilibrado ao processo decisório das CIR.

Finalmente, quando consideramos os debates no âmbito das reuniões do colegiados, observase que os principais convidados para realizar apresentações são gestores e técnicos das secretarias estaduais $(84,1 \%)$ e municipais de saúde $(81,1 \%)$, corroborando o argumento de que as CIR consistem em um dispositivo político-institucional que reflete um pacto federativo entre as esferas estadual e municipal. Cabe destacar ainda a crescente participação dos apoiadores do COSEMS na dinâmica de trabalho desses colegiados.

\section{Qualidade do processo decisório}

Como pode ser visto no Quadro 3, a realização de reuniões técnicas prévias aos encontros de consensos do colegiado não é uma atividade regular, ocorrendo em pouco mais de um terço das CIR. Na maioria dos casos, tais reuniões ocorrem apenas quando há convocação da coordenação/ presidência, da secretaria executiva ou de alguma câmara técnica. $\mathrm{O}$ cuidado com a segurança jurídica das decisões tem adquirido mais atenção, uma vez que a grande maioria das CIR adota quórum mínimo expressivo de presença dos membros para composição de consensos.

A presença de gestores e técnicos convidados atuando tanto na realização de informes quanto no desenvolvimento dos debates é característica corrente em mais de $2 / 3$ das CIR, o que permite ampliar o volume de informações e a diversidade de olhares sobre os principais problemas abordados nas reuniões.

Entretanto, quando analisamos os principais temas discutidos, percebemos a predominância de problemas imediatos da gestão do SUS, com pouco prioridade para o planejamento da regionalização, que deveria ser sua atribuição essencial. Assim, podemos ver que a maioria das CIR concentra seus esforços no debate sobre a pactuação fluxos intermunicipais, o credenciamento de políticas federais, os problemas de saúde pública e os repasses financeiros da SES.

\section{Discussão e conclusão}

\section{Um complexo de Governança Regional Institucionalizado, porém subfinanciado e focado em questões emergenciais}

\section{As CIR como espaços institucionalizados de Governança Federativa Regional do SUS}

Os resultados mostram que as CIR são um componente fundamental do sistema nacional de governança federativa do SUS, na medida em que consistem na extensão do modelo de federalismo cooperativo que fundamentou a construção da CIT e das CIB para as regiões de saúde nos estados brasileiros ${ }^{25}$.

Esse complexo de instâncias colegiadasregionais, como mostram os dados acima, está legalmente instituído em todos os estados por deliberação das respectivas CIB, possui regras de funcionamento definidas e publicadas na forma de regimentos internos, foi implementado em praticamente todas as regiões do país, com raras exceções, apresentou poucas interrupções de funcionamento, realiza reuniões mensais com significativa frequência de comparecimento de seus membros.

Portanto, da perspectiva da legitimidade institucional e da adesão dos estados e municípios, não restam dúvidas de que esse sistema de governança está plenamente estabelecido como espaço de consolidação do pacto federativo setorial, na medida em que é reconhecido como lócus de tomada de decisão e resolução de conflito em âmbito regional.

$\mathrm{O}$ mesmo pode ser dito quando analisamos os dados relativos ao equilíbrio federativo, pois os dados mostram que, em todos os estados, a implementação das CIR ocorreu de forma conjunta, a composição do colegiado é ampla e envolve representante das esferas municipal e estadual, a definição das pautas é influenciada por solicitações das SMS e das SES, e os convidados para realizar informes e participar nos debate provém de ambos os lados. Obviamente que o equilíbrio não será uniforme em todos os estados e municípios, considerando tanto as assimetrias de recursos financeiros, assistenciais, gerenciais e técnicos quanto o protagonismo que cada ente exerceu nas trajetórias particulares de implementação de cada CIR em cada região.

Três fatores relacionados ao processo de construção federativa do SUS podem ser apontados como fundamentais para se obter a expressiva institucionalização desse sistema de comissões regionais. O primeiro consiste no processo pio- 
neiro e inovador, conduzido por alguns estados, na década 1990, de criação das CIBs regionais como dispositivo para conformar um sistema de governança territorial mais capilarizado do que as CIB, além da manutenção das estruturas regionais de gestão, como as diretorias regionais de saúde, que definem a presença das SES nas regiões do estado.

O segundo é o papel exercido pelo Ministério da Saúde na indução de arranjos institucionais prévios às CIR, em especial, os CGR, que estimularam a nacionalização dessas inovações. Finalmente, cabe apontar o papel dos COSEMS na implementação das presidências regionais e dos projetos de apoio institucional nos territórios, em vários estados, quevalorizou as lideranças regionais dos gestores e conferiu destaque aos desafios da consolidação do SUS nas regiões de saúde ${ }^{26}$.

Em síntese, o sistema de governança interna das CIR é o resultado de um processo de difusão de inovações impulsionado pela ação contínua e cooperativa das três esferas da federação brasileira, em movimentos complementares ao longo das três últimas décadas.

\section{As CIR como instâncias subfinanciadas e concentradas nas questões emergenciais da gestão local do SUS}

Entretanto, o mesmo padrão de governança não se observa nos demais atributos de organização institucional das CIR. As situações mais críticas foram observadas na qualidade da estrutura e condições de funcionamento dessas instâncias, em virtude do baixo aporte de recursos financeiros, gerenciais e técnicos a elas disponibilizados.

Apesar de grande parte das CIR possuir espaço próprio disponibilizado pelas SES, na maioria dos casos esses não são exclusivos, ou seja, nem sempre estão inteiramente à disposição das atividades das CIR. Esse padrão de precariedade se reflete principalmente na infraestrutura, em geral, reduzida ao mínimo necessário, tendo sido frequentes os casos de gestores que mencionaram, nas oficinas regionais, que aportavam computadores, telefones celulares, carros e recursos financeiros próprios para sustentar o desenvolvimento de atividades cotidianas prévias e posteriores às reuniões do colegiado.

Assim, embora a grande maioria das CIR tenha reportado a presença de uma secretaria executiva com funcionamento regular, a mesma possui, em geral, apenas um funcionário, além do próprio secretário executivo, o que impõem expressivas limitações sobre a capacidade de co- ordenação gerencial das atividades cotidianas de articulação regional. Em boa parte dos casos, ambos são funcionários estaduais ou municipais que deslocam parte de sua carga horária semanal para as atividades da CIR e, portanto, não possuem remuneração específica para o exercício dessas funções.

Da mesma forma, não há, na quase totalidade dos casos, alocação orçamentária exclusiva para o custeio das atividades das CIR, sendo os recursos utilizados na compra de passagens, serviços de terceiros e material de consumo, principais gastos, provém do orçamento geral das SES e SMS, o que não garante fonte regular de financiamento dessas instâncias. Tal situação gera insegurança sobre a estabilidade de funcionamento das CIR, desmotivando gestores e técnicos e reduzindo as expectativas de ambos sobre essas no planejamento e na gestão regional do SUS. Além disso, os aportes de recursos federais para apoiar o financiamento dessas instâncias foram interrompidos na última metade de década, sinalizando perda de legitimidade e relevância de seu papel nas estratégias nacionais de coordenação federativa do SUS.

Além do subfinanciamento, a concentração exclusiva dos debates e decisões em temas e questões emergenciais da gestão dos sistemas locais e regionais de saúde consiste em outra limitação relevante identificada na pesquisa, pois indica um deslocamento dessas instâncias de sua função essencial que consiste em debater e deliberar sobre o planejamento regional de médio e longo prazo, definindo estratégias para reconfigurar, de maneira maia racional, o financiamento e a organização da rede de serviços na região.

Outra questão relevante identificada no conteúdo das reuniões e consensos foi o uso dessas instâncias como espaço para elaboração e aprovação de planos operativos de programas e políticas federais para implementação de linhas de cuidado específicas, denominadas redes temáticas, como a Rede Cegonha. Isso mostra o potencial das CIR como dispositivo de coordenação federativa na implementação de políticas nacionais, mas também pode esvaziar a coordenação estadual dessas estratégias de natureza macrorregional, acentuando tendências de coordenação direta entre o Ministério da Saúde e os municípios.

Portanto, o principal desafio para a sustentação e o aperfeiçoamento desse sistema de governançainterna das regiões de saúde consiste na continuidade da ação conjunta das três esferas, em especial, no aporte de iniciativas nacionais $\mathrm{e}$ 
estaduais que possam reduzir a precariedade observada na infraestrutura de funcionamento e no volume de recursos financeiros disponível para a operacionalização das atividades essenciais das CIR. Da mesma forma, é importante que o foco de atuação dessas instâncias seja ampliado para abranger tambémtemas relacionados ao planejamento regional em saúde, para além da concentração atual em questões típicas da gestão cotidiana da pactuação intermunicipal de fluxos de consultas e exames e do subfinanciamento do SUS 27,28 .

\section{Colaboradores}

Os autores trabalharam em conjunto na concepção e no delineamento do artigo. AM Ouverney foi o responsável pela redação e pela análise e interpretação dos dados. ALB Carvalho, JM Ribeiro e MR Moreira foram responsáveis pela revisão crítica do texto.

\section{Referências}

1. Fleury S. Democracia e Inovação na Gestão Local da Saúde. Rio de Janeiro: Editora Fiocruz/Centro Brasileiro de Estudos de Sáude; 2014.

2. Ribeiro JM. Conselhos de saúde, comissões intergestores e grupos de interesses no Sistema Único de Saúde (SUS). Cad Saude Publica 1997; 13(1):81-92.

3. Albuquerque MV, Lima, LD, Oliveira RAD, Scatena JHG, Martinelli NL, Pereira AM. Governança regional do sistema de saúde no Brasil: configurações de atores e papel das Comissões Intergovernamentais. Cien Saude Colet 2018; 23(10):3151-3161.

4. Ouverney AM, Noronha JC. Modelos de organização e gestão da atenção à saúde: redes locais, regionais e nacionais. In Fundação Oswaldo Cruz. A saúde no Brasil em 2030 - prospecção estratégica do sistema de saúde brasileiro: organização e gestão do sistema de saúde. Rio de Janeiro: Fiocruz/Ipea/MS/Secretaria de Assuntos Estratégicos da Presidência da República; 2013. p. 143-182.

5. Viana ALD, Lima LD, Ferreira MP. Condicionantes estruturais da regionalização na saúde: tipologia dos Colegiados de Gestão Regional. Cien Saude Colet 2010; 15(5):2317-2326.

6. Silveira RM, Santos AM, Carvalho JA, Almeida PF. Ações da Comissão Intergestores Regional para gestão compartilhada de serviços especializados no Sistema Único de Saúde. Physis 2016; 26(3):1809-4481.

7. Vianna RP, Lima LD. Colegiados de Gestão Regional no estado do Rio de Janeiro: atores, estratégias e negociação intergovernamental. Physis 2013; 23(4):10251049 . 
8. Santos L, Andrade LOM. SUS: o espaço da gestão inovada e dos consensos interfederativos - aspectos jurídicos, administrativos e financeiros. Campinas: Instituto de Direito Sanitário Aplicado; 2007.

9. Machado CV. Direito universal, politica nacional: o papel do Ministério da Saúde na política de saúde brasileira de 1990 a 2002. Rio de Janeiro: Editora do Museu da República; 2007.

10. Abrúcio FL. A coordenação federativa no Brasil: a experiência do período FHC e os desafios do governo Lula. Rev Sociol Polit 2005; 24:41-67.

11. Ouverney AM, Fleury S. Polarização federativa do SUS nos anos 1990: uma interpretação histórico-institucionalista. Rev Administr Publica 2017; 51(6):1085-1103.

12. Miranda A. Processo decisório em Comissões Intergestores do Sistema Único de Saúde: governabilidade resiliente, integração sistêmica (auto) regulada. Rev Polit Planej Gestao Saude 2010; 1(1):117-139.

13. Miranda AS. Análise Estratégica dos Arranjos Decisórios na Comissão Intergestores Tripartite do Sistema Único de Saúde [tese]. Salvador: Universidade Federal da Bahia; 2003.

14. Viana AL, Machado CV. Descentralização e coordenação federativa: a experiência brasileira na saúde. Cien Saude Colet 2009; 14(3):807-817.

15. Brasil. Decreto no 7.508, de 28 de junho de 2011. Regulamenta a Lei no 8.080 , de 19 de setembro de 1990 , para dispor sobre a organização do Sistema Único de Saúde - SUS, o planejamento da saúde, a assistência à saúde e a articulação interfederativa, e dá outras providências. Diário Oficial da União 2011; 29 jun.

16. Brasil. Ministério da Saúde (MS). Portaria GM/MS no 01, de 22 de fevereiro de 2006. Divulga o Pacto pela Saúde 2006 - Consolidação do SUS e aprova as Diretrizes Operacionais do Referido Pacto. Diário Oficial da União 2006; 23 fev.

17. Brasil. Ministério da Saúde (MS). Portaria CIT/GM/ MS no 01, de 29 de setembro de 2011. Estabelece diretrizes gerais para a instituição de Regiões de Saúde no âmbito do Sistema Único de Saúde (SUS), nos termos do Decreto no 7.508, de 28 de junho de 2011. Diário Oficial da União 2011; 30 set.

18. Moreira MR, Ribeiro JM, Ouverney AM. Obstáculos políticos à regionalização do SUS: percepções dos secretários municipais de Saúde com assento nas Comissões Intergestores Bipartites. Cien Saude Colet 2017; 22(4):1097-1108.

19. Carvalho ALB, Ouverney AM, Carvalho MGO, Machado NMS. Enfermeiros(as) gestores(as) no Sistema Único de Saúde: perfil e perspectivas com ênfase no Ciclo de Gestão 2017-2020. Cien Saude Colet 2019; 25(1):211-222.
20. Machado CV, Lima LD, Viana ALA, Oliveira RG, Iozzi FL, Albuquerque MV, Scatena JHG, Mello GA, Pereira AMM, Coelho APS. Federalismo e política de saúde: comissões intergovernamentais no Brasil. Rev Saude Publica 2014; 48(4):642-650.

21. Santos AM, Giovanella L. Governança regional: estratégias e disputas para gestão em saúde. Rev Saude Publica 2014; 48(4):622-631.

22. Barbazza E, Tello JE. A review of health governance: definitions, dimensions and tools to govern. Health Policy 2014; 116(1):1-11.

23. Frederickson G. Whatever happened to public administration? governance, governance everywhere. In: Ferlie E, Lynn L, Pollitt C. The Oxford handbook of public management. Oxford: Oxford University Press; 2005. p. 282-304.

24. Survey Monkey [Internet]. [acessado 2017 mar 12]. Disponível em: https://pt.surveymonkey.com/.

25. Palotti PLM, Machado JA. Coordenação federativa e a "armadilhada decisão conjunta": as comissões de articulação intergovernamental das políticas sociais no Brasil. Dados 2014; 57(2):399-441.

26. Shimizu HE, Cruz MS, Bretas Júnior N, Schierholt SR, Ramalho WM, Ramos MC, Mesquita MS, Silva EN. O protagonismo dos Conselhos de Secretários Municipais no processo de governança regional. Cien Saude Colet 2017; 22(4):1131-1140.

27. Carvalho ALB, Jesus WLA, Senra IMVB. Regionalização no SUS: processo de implementação, desafios e perspectivas na visão crítica de gestores do sistema. Cien Saude Colet 2017; 22(4):1155-1164.

28. Biscarde DGS, Vilasbôas ALQ, Trad LAB. Consenso e pactuação regional entre gestores do SUS no nordeste do Brasil. Cien Saude Colet 2020; 24(12):4519-4527.

Artigo apresentado em 02/04/2020

Aprovado em 13/08/2020

Versão final apresentada em 15/08/2020

Editores-chefes: Romeu Gomes, Antônio Augusto Moura da Silva 